\title{
Comprehensive course management and delivery using POISE-CIS
}

\author{
PETER A. HORNBY \\ State University of New York College at Plattsburgh, Plattsburgh, New York
}

\begin{abstract}
At SUNY-Plattsburgh, we are using the POISE-CIS course management and delivery software to teach one section of introductory psychology each semester. Although this course uses a traditional textbook and covers the same material as most introductory psychology courses, it uses a self-paced mastery-based approach to learning and is managed and delivered over the Plattsburgh computer network. Students receive assignments, take on-line diagnostic assessments, receive feedback, and communicate with the instructor over the campus network. In a departmental laboratory facility, students also work with a computerized tutorial, complete computerized learning activities, take supervised on-line exams, and consult with teaching assistants. The present paper describes the overall design of the course as well as the specific characteristics of the course as it was offered in the spring of 1995, at which time data were collected on student attitudes toward computers.
\end{abstract}

At SUNY-Plattsburgh, one section of introductory psychology has traditionally been offered following the Personalized System of Instruction (PSI). This approach, which is also known as the Keller Plan (Keller, 1968; Keller \& Sherman, 1974), features individualized student self-pacing, mastery learning, extensive self-study, and frequent testing and evaluation. Considerable research (Kulik, Kulik, \& Cohen, 1979; Ryan, 1974) has demonstrated that such a self-paced mastery-based course can be highly successful in achieving traditional instructional goals and may also contribute to the enhancement of such skills as goal setting, time management, and effective use of study strategies. In comparison with more traditional formats, PSI frequently leads to higher student achievement, higher course ratings, and increased student effort.

Although the flexibility inherent in the PSI approach is attractive to a substantial number of students and many campuses offer courses of this type, the individualized nature of the course necessitates a considerable amount of instructor management as well as relatively complex record keeping. Fortunately, the availability of computerbased instructional technologies now makes it possible to increase the flexibility and individualization inherent in the PSI format. At the same time, it eliminates the need for hard-copy testing and the tedious record keeping traditionally associated with this type of course. At SUNY-Plattsburgh, we have taken advantage of the avail-

The development of this course was supported in part by a grant from the SUNY Office of Educational Technology to M. D. Anderson and the author, as well as funding from the SUNY Student Computer Access Program (SCAP). The author is grateful to M. D. Anderson for her continued help and support in the development of this project. Correspondence should be addressed to P. A. Hornby, Department of Psychology, State University of New York College at Plattsburgh, Plattsburgh, NY 12901 (e-mail: hornbypa@splava.cc.plattsburgh.edu). able technology to develop and offer a computer-managed self-paced introductory psychology course of this nature.

\section{Background and Overview}

Approximately 2 years ago, we began the process of computerizing our existing self-paced introductory psychology course. Our goal was to provide assignments, deliver assessments, provide feedback, and maintain all course records by computer. We also wanted to use computer technology to deliver instructional materials, to provide remedial exercises, to present demonstrations, and to support communication between students and the instructor. In addition, we wanted to make the course accessible at any time of the day or night from a variety of locations both on and off campus and to allow students to use and strengthen their computer skills.

The course has now been offered for three semesters, with enrollments of approximately 50 students each semester. Because it is a relatively new course format, the specific characteristics of the course are undergoing considerable development; however, the overall design of the course is now fairly well established. Within the constraints of the normal semester, students work through the course at their own pace. They are not required to attend any classes, and there are no traditional lectures. Students read and study a traditional textbook, they complete exercises in a workbook, and they engage in activities in a laboratory facility. As they work through the text, students take on-line assessments over the network to assess their knowledge. After demonstrating mastery of a chapter, they can go on to the next chapter. When students complete a unit, they take a supervised on-line test. Students can also earn points by completing any of a large number of learning activities, which include computer exercises, videos, journal articles, lectures, and research participation. Although students proceed at their 
own pace, there are specified dates by which a minimum level of achievement must be reached.

The following sections of this paper provide a more complete description of the design and implementation of this course as it was offered during the spring semester of 1995. In addition, a summary of student activities and outcomes for that semester will be presented. During this semester, the students in the course were given the opportunity to participate in a study designed to evaluate the relationship between course participation and student's attitudes and beliefs about computers (Anderson \& Hornby, 1996).

\section{Course Delivery Software}

The course is managed by the POISE-CIS (formerly LMX) course development and delivery system produced by Campus America. This software is designed to run on Digital Equipment Corporation's VAX and Alpha family of servers; at Plattsburgh, we are currently running on a networked VAX 6610. This software system contains features that can be used to support curriculum design and development, enrollment management, course delivery, individual assessment, record keeping, and report generation. The system has been loaded with the complete course structure, including course objectives, reading assignments, learning activities, learning resources, and assessment materials. At the beginning of the semester, student names are loaded into the system from the course registration files, and students are provided with individual password-protected accounts. From then on, the system tracks each student's progress through the course, delivers assignments, and administers assessments based on each student's status. It also maintains comprehensive records of each student's activities and performance. Individual records are available to a student at any time, and both individual records and class records are available to the instructor. Since the course runs on a networked server, it can be accessed from a variety of locations across campus, including student dorms. Off campus, students can access the course via telnet or by modem.

Although the initial work involved in setting up the delivery system greatly exceeded our expectation, we have, in general, been pleased with the capabilities and performance of the POISE-CIS system. One continuing problem results from the fact that the system was designed for use on the DEC VT family of terminals. This means that students using different keyboards and/or different platforms must learn alternative keys for certain functions. During the spring 1995 semester, this involved providing students with separate instructions for accessing the course from a total of five different platforms/locations across campus. This created confusion and added to the difficulty that students initially experienced in learning to use the software. In terms of student record keeping, assignment delivery, and development and administration of assessments, the software performs at a satisfactory level. The student interface, however, could be significantly improved to ease the difficulty of navigating through the available features.

\section{Textbook}

The course uses a standard textbook (Zimbardo \& Weber, 1994) and study guide/workbook (Gram, Weber, \& Zimbardo, 1994). The text was selected with the help of student input and was chosen because the content appears to be current and accurate, the writing is clear, and the material appears to be relatively understandable without the need for supplementary lectures. The available study guide/workbook is one of the most comprehensive available and provides the student with a large number of learning exercises that aid in understanding and mastering the material. Also, there is a very extensive test bank, with items keyed to specific topics and categorized as factual, conceptual, or applied. Finally, a computerized study guide is available for the text. Since students are highly dependent on the textbook and the workbook, the quality of these materials is very important to the success of the course. After three semesters, it appears that the students find these resources to be satisfactory.

\section{Initial Meeting}

On the first day of the semester, all students are required to come to the department laboratory to obtain the course syllabus. The syllabus contains a detailed outline of the course, including specific requirements, deadlines, learning activity options, grading procedures, and general instructions for accessing the course by computer. After reading the syllabus, students must sign a course contract indicating that they understand what is expected of them. In addition, students must sign up for a 1-h tutorial that introduces them to the POISE-CIS system and teaches them to use the campus e-mail utility. During the tutorial, students also take an on-line sample test and are shown how to access other learning activities available on the computers in the lab.

\section{Computer Facilities}

There are no regularly scheduled classes. Instead, a computer laboratory facility is available to students $20 \mathrm{~h}$ a week. The laboratory is housed within the psychology department and is also used to support other instructional activities within the psychology curriculum. While in the lab, students may obtain help on any aspect of the course. The lab is equipped with 16 networked PCs and two printers that are also linked to the campus network. Students may use these computers to take assessments, work with a computerized tutorial, complete optional demonstrations and simulations, and access their VAX accounts for e-mail. The lab is staffed by a graduate laboratory manager and undergraduate teaching assistants who help students with their use of the computer, tutor students on the course content, and/or work with them on the development and improvement of their study skills.

In addition to the departmental laboratory, students may access the POISE-CIS system from other computer laboratories located on the campus. The campus phone service also supports data-line access from dormitory rooms throughout the campus. During the spring 1995 se- 
mester, approximately one fifth of the students on campus had access to the network from dormitory facilities.

\section{Self-Assessment}

Students are required to achieve mastery of each chapter of the text. They do this by completing the assignments that are indicated in the course outline and by taking on-line "self-assessments." Whenever students log on to the course, they are told what their next scheduled activity is. These activities include reading and studying chapters of the textbook, completing exercises in the workbook, working through activities on the electronic study guide, and taking scheduled assessments. If students indicate that they have completed the appropriate work, the opportunity to take a scheduled assessment is provided. If students choose to take the assessment, it is individually generated from the appropriate pool of questions that are available on the system. Each self-assessment consists of two questions (multiple choice and true/false) for each of the 12-14 major objectives covered in the chapter. Each objective is linked to about 20 questions, which are classified as factual, applied, or conceptual. Each assessment contains approximately $40 \%$ factual, $30 \%$ applied, and $30 \%$ conceptual questions based on the taxonomy provided. The assessment is delivered on line.

When students finish taking an assessment, they can review and change the answers to any questions and then have the assessment scored. After their assessments are scored, students are provided with a comprehensive report that can be viewed on the screen and/or printed. Reports include total percent correct answers, general feedback about performance, explanations for incorrect answers, and recommendations for which objectives to continue to work on and which parts of the text to review. Students must obtain a score of $75 \%$ on a chapter assessment before continuing to the next chapter. If they fail to obtain $75 \%$, the system requires that they wait $12 \mathrm{~h}$ before taking another assessment on the same chapter. If students fail to achieve $75 \%$ after three attempts, they must meet with a teaching assistant to review the material that is causing difficulty as well as to discuss their study methods before making another attempt. Although student selfassessments are unsupervised and are frequently taken from remote sites, students are encouraged to simulate actual testing conditions in order for the assessment to be a valid appraisal of their learning. Scores on self-assessments do not count toward a student's final grade.

\section{Unit Testing}

After mastering the three or four chapters that comprise a unit, students report to the laboratory to take a supervised unit test. There are four unit tests throughout the semester, and each test has a published deadline by which it must be completed unless alternative arrangements have been made in advance. Questions on the unit test are sampled from the same general pool of questions as the self-assessments, with the same breakdown of factual, applied, and conceptual items. Unit tests are also individually generated for each student and consist of a total of 50 questions, with no more than one question per objective. As long as students have completed the unit test by the date scheduled in the syllabus, they may repeat the test after $24 \mathrm{~h}$ in order to replace a failing grade. After the published date and for second attempts, the maximum grade a student can achieve is a minimal passing score. The following breakdown of grades was used during the spring 1995 semester: $A=85-100, B=75-$ $84, C=65-74, D=50-64$, and $E=<50$. Although this grading profile may appear quite lenient, it is considered appropriate since students are responsible for all of the material covered in the textbook. There are approximately 650 questions that can appear on any individual unit test. Even the best students find it difficult to achieve scores in the $90 \mathrm{~s}$. Scores on each of the four unit tests contribute $20 \%$ toward the student's final course grade.

\section{Learning Activities}

In addition to learning the material in the textbook, students choose from a variety of other learning activities. These include a large collection of computerized demonstrations and simulations, including activities from Psychabilities (Ransdell, 1992), Journey (Anderson, Hornby, \& Pearson, 1990), and Discovering Psychology (Levy, Levy, Morgan, \& Yunker, 1988). In addition, we have an extensive set of videos for students to view or sign out at the college library, where we also have a set of carefully selected supplementary readings. Students may also attend approved public lectures on topics relevant to the course and can participate in approved research projects. Each activity is assigned a point value ranging from 1 to 8 , and students must accumulate a total of 50 points during the semester. Credit for each activity requires the preparation and submission of written work, which may be done electronically. These activities are graded on a pass/fail basis, and students may repeat the activity if necessary to earn the associated points. On the basis of their own learning preferences, students may select any combination of these activities to meet the course requirements, and the total points earned count as an additional $20 \%$ of the student's final course grade.

\section{E-Mail Communication}

All students in the course are required to use e-mail for communication with the instructor and the teaching assistants. Written work can also be submitted by e-mail. Students may contact the instructor at any time as issues arise related to course administration, content, or other matters. In addition, the instructor and the teaching assistants can communicate with individual students, selected groups, or the entire class. Weekly messages announcing special events, providing reminders of upcoming deadlines, and providing progress reports are sent out by the instructor using a distribution list.

\section{Student Performance (Spring 1995)}

During the spring 1995 semester, a total of 50 students registered for the course. Since this was only the second 
time that the course had been offered under computer management, many students who enrolled did not know the course would be computer managed. Nevertheless, only 2 students requested to change to the more traditional lecture course after learning about the nature of the course. However, as is often the case with self-paced courses (Reiser, 1984; Roberts, Fulton, \& Semb, 1988), quite a few students failed to maintain reasonable progress, and, by midterm, a total of 10 students had dropped the course. A review of the withdrawal applications revealed that none of these students reported difficulty with the computer management as a reason for their withdrawal. A total of 38 students continued with the course for the full semester.

Not counting the relatively high number of withdrawals, the final course grades for the semester were fairly normally distributed, with $3 \mathrm{As}, 7 \mathrm{Bs}, 18 \mathrm{Cs}, 6 \mathrm{Ds}$, and 4 Es. This distribution is similar to that achieved by students participating in the more traditional lecture sections of the course, although somewhat lower than what was generally the case for the self-paced course prior to computer management.

During the spring 1995 semester, a total of 307 e-mail messages were received by the instructor. An analysis of these messages revealed that $42 \%$ concerned course requirements/policy issues, and another $12 \%$ were questions about using the computer system. Acknowledgments of material sent by the instructor constituted another $22 \%$ of the messages, and $11 \%$ were considered social/ unclassifiable. Only $13 \%$ of the total messages dealt with actual course content, and these came from a total of 7 students.

Although a few students occasionally required the maximum of five attempts to demonstrate mastery on a self-assessment, the average number of attempts was 1.36 per chapter. A review of the self-assessment data stored by the system revealed that most students improved considerably during the semester in their ability to achieve mastery on their first attempt. Although the data are only informal, it appears as if the majority of students accessed the system from one or more of the general computer laboratories on campus, and about a quarter of the students had access from their home or their dorm. The remaining students came to the laboratory to take their assessments.

Although the required learning activities consisted of a variety of options, the most popular choice was completing the computerized activities and worksheets provided in the laboratory. Of the 50 required points, on average, 32 were earned by completing computer activities, with a large number of students earning almost all their points in this manner. The remaining activity points were earned, in order of frequency, by reading journal articles, participating in research, and attending public lectures.

\section{Conclusions}

We did not collect any formal evaluation data during the first year of offering the course in order to allow time for the general course operation to become established; however, a considerable amount of informal feedback suggests that the course was generally achieving its goals. Many students reported that they appreciated the relatively unlimited access to the self-assessments and the immediate and extensive feedback provided. The electronic study guide available in the laboratory was used extensively. A large number of students accessed the course remotely and used the system late at night and on the weekends. Students involved in athletics did not need to be concerned about missed classes, and they could easily work ahead or catch up later. Students who were ill and fell behind could easily be accommodated. Despite the difficulty involved in learning to use POISECIS, after two-and-one-half semesters, not a single student has complained to the instructor about the need to learn the computer system or the difficulty of the course material, although the grades clearly show that it is not an easy course.

It is anticipated that the course will continue to undergo development and enhancement, particularly as better technology becomes available and more students become comfortable with the use of computers and acquire their own hardware. Working with alternative approaches to reducing student procrastination will be a major activity. Thus far, however, our experience suggests that a computer-managed self-paced introductory psychology course can provide a viable alternative to the more traditional course formats.

\section{REFERENCES}

Anderson, M. D., \& Hornby, P. A. (1996). Computer attitudes and the use of computers in psychology courses. Behavior Research Methods, Instruments \& Computers, 28, 341-346.

Anderson, M. D., Hornby, P. A., \& Pearson, L. (1990). Journey [Computer program]. New York: Harper \& Row.

Gram, P. C., Weber, A. L., \& Zimbardo, P. G. (1994). Study guide and workbook to accompany psychology. New York: Harper Collins.

KELLER, F. S. (1968). Good-bye, teacher... Journal of Applied Behavior Analysis, 1, 79-89.

Keller, F. S., \& Sherman, J. G. (1974). The Keller plan handbook. Menlo Park, CA: W. A. Benjamin.

Kulik, J. A., KulIK, C. C., \& CoHEN, P. A. (1979). A meta-analysis of outcome studies of Keller's Personalized System of Instruction. American Psychologist, 34, 307-318.

Levy, C. M., Levy, G. J., Morgan, M. D., \& YunKer, D. (1988). Discovering psychology. [Computer program]. Bayport, NY: Life Science.

Ransdell, S. (1992). Psychabilities [Computer program]. Boston, MA: Houghton Mifflin.

REISER, R. A. (1984). Reducing student procrastination in a personalized system of instruction course. Educational Communication \& Technology: A Journal of Theory, 32, 41-49.

Roberts, M. S., Fulton, M., \& SemB, G. (1988). Self-pacing in a personalized psychology course: Letting students set the deadlines. Teaching of Psychology, 15, 89-92.

RYAN, B. A. (1974). Keller's personalized system of instruction: An appraisal. Washington, DC: American Psychological Association.

Zimbardo, P. G., \& Weber, A. L. (1994). Psychology. New York: Harper Collins.

(Manuscript received November 13, 1995; accepted for publication January 3,1996.) 